\title{
Cardiac Manifestations in Adult Sickle Cell Disease Patients at a Tertiary Care Hospital in Chhattisgarh, India
}

\author{
Smit Shrivastava ${ }^{1}$, Animesh Chaudhary ${ }^{2}$, Prabhat Pandey ${ }^{3}$ \\ 1, 2,3 Department of Cardiology, Advanced Cardiac Institute, Pt. J.N.M. Medical \\ College \& Dr. B.R.A.M. Hospital, Raipur, Chhattisgarh, India.
}

\section{ABSTRACT}

\section{BACKGROUND}

Sickle cell disease is the commonest haemoglobinopathy. Recent advanced therapeutic approaches are enabling the sickle cell patients to survive beyond adulthood.

\section{METHODS}

The study provides important data on cardiovascular abnormalities in sickle cell disorder in Chhattisgarh by employing a non-invasive method of two-dimensional colour Doppler echocardiography.

\section{RESULTS}

The present study suggests that sickle cell disease has association with left ventricular diastolic dysfunction and pulmonary artery hypertension and no association with other echocardiographic findings including left ventricular dimensions and functions. The association is further affected by the presence of moderate to severe anaemia (haemoglobin < 8.9 gm \%), higher urea ( $>19 \mathrm{mg} / \mathrm{dL}$ ), creatinine $(0.8 \mathrm{mg} / \mathrm{dL})$ and diastolic blood pressures $(<69 \mathrm{mmHg})$. The age, gender and systolic blood pressures of the subject were not found to impact echocardiographic parameters.

\section{CONCLUSIONS}

The present study suggests that sickle cell disease affects left ventricular diastolic dysfunction and pulmonary artery hypertension but does not affect the other echocardiographic dimensions and functions. The association is further affected by the presence of moderate to severe anaemia, higher urea, creatinine and diastolic blood pressures. The age, gender and systolic blood pressure do not influence echocardiographic parameters.

\section{KEY WORDS}

Adult, Sickle Cell Disease, Echocardiography, Ventricular Function, Anaemia
Corresponding Author:

Dr. Smit Shrivastava,

Cardiology Clinic, C9, Sector 2,

Avanti Vihar - 492006, Raipur,

Chhattisgarh, India.

E-mail: dr.smit.shrivastava@gmail.com

DOI: $10.14260 /$ jemds/2021/328

How to Cite This Article:

Shrivastava S, Chaudhary A, Pandey P. Cardiac manifestations in adult sickle cell disease patients at a tertiary care hospital in Chhattisgarh, India. J Evolution Med Dent Sci 2021;10(21):1567-1574, DOI: 10.14260/jemds/2021/328

Submission 15-12-2020,

Peer Review 22-03-2021,

Acceptance 29-03-2021,

Published 24-05-2021.

Copyright (C) 2021 Smit Shrivastava et al This is an open access article distributed under Creative Commons Attribution License [Attribution 4.0 International (CC BY 4.0)] 


\section{BACKGROUND}

Sickle cell disorder (SCD) is the first diagnosed disease that is linked to the haemoglobin protein and is genetically characterised. It is an autosomal recessive disorder that occurs in regions with high incidence of falciparum malaria in SubSaharan Africa, Mediterranean countries and Southern India. ${ }^{1}$ The SCD affects $2,00,000$ to $3,00,000$ newborn every year worldwide. $^{2}$

The distorted shape and reduced flexibility from polymerisation of deoxygenated sickle haemoglobin within the erythrocyte, reduces membrane fluidity to alter its rheological properties in flowing blood. The resultant physical entrapment and adhesive interactions of red blood cellleukocyte-endothelial cause obstruction of the microvasculature.3,4 The vascular obstruction manifests as ischemia-reperfusion injury to vital organs, and infarction of all vital organs such as the kidneys, spleen, muscles, liver, brain, bones and lungs. The progressive proliferative systemic vasculopathy in SCD affects the heart with pulmonary artery hypertension (PAH) and left ventricular diastolic dysfunction (LVDD).

In addition, chronic anaemia in SCD results in cardiac chamber dilatation and compensatory increase in left ventricular (LV) mass which is accompanied by left ventricular diastolic dysfunction. Pulmonary hypertension and left ventricular diastolic dysfunction are independent risk factors for mortality in SCD. 5

Despite a remarkable increase in SCD patients' longevity over the past few decades, the mortality and morbidity due to cardiovascular and pulmonary complications stays high. Numerous clinicopathological studies have demonstrated that patients with pulmonary hypertension and diastolic left ventricular dysfunction are especially high-risk subgroups. These cardiopulmonary complications contribute to a markedly low functional capacity and associated high risk of both sudden death and severe multi-organ dysfunction. Though the left ventricular ejection fraction (LVEF) is preserved in SCD. 6

There is lack of data on sickle cell disease from the newly formed Chhattisgarh state despite being in a sickle prevalent region. The cardiac effects of sickle cell disease have been studied in blood pressure indices and electrocardiogram from Chhattisgarh.7,8 Thus, the main objective of this study is to furnish critical information on cardiovascular abnormalities in SCD in Chhattisgarh employing non-invasive 2-dimensional colour Doppler echocardiography.

\section{METHODS}

This study comprising 100 cases was conducted in the Department of Medicine, Pt. Jawaharlal Nehru Memorial Medical College and Dr. B.R.A.M. Hospital, Raipur (C.G.) among the patients presenting in Outpatient Department and admitted in the Medicine ward from December 2013 to September 2015. The sample size of 50 sickle cell disease subjects and 50 control subjects were determined to facilitate convenience and comparison. The study was approved by ethics committee. This was a cross sectional study.

\section{Inclusion Criteria for Study Group}

1. Patient with sickle cell disease (HbSS) or sickle cell trait (HbSA) blood type on haemoglobin ( $\mathrm{Hb}$ ) electrophoresis.

2. Age group between 16 years to 70 years.

\section{Exclusion Criteria for Study Group}

1. All patients with sickle cell anaemia with other cardiac diseases like valvular heart disease.

2. Ischemic and hypertensive heart disease, congestive heart failure and cardiomyopathies were excluded from the study.

3. Patients with other chronic illnesses such as chronic kidney disease.

4. Pulmonary hypertension other than sickle cell anaemia e.g., idiopathic, familial or associated with other diseases like collagen vascular disease, congenital shunts between the systemic and pulmonary circulation, portal hypertension, valvular disease or chronic obstructive pulmonary disease (COPD).

5. Other causes of LVDD like long standing hypertension, aortic stenosis, diabetes etc.

\section{Methods}

A total of 100 patients who fulfilled the inclusion criteria were included for the study. Patient's informed consent was taken. Detailed clinical history was recorded which included age, sex, presenting complaints, past, personal and family history. All patients underwent complete clinical examination including pulse, blood pressure, general examination, systemic examination including neurological examination and echocardiography with colour doppler using transthoracic echocardiography was performed with the use of the Mindray M7 echocardiography machine. Cardiac measurements were performed according to American Society of Echocardiography guidelines. ${ }^{9}$

The LV ejection fraction was assessed using M-Mode with help of Teichholz equations. Tricuspid regurgitation jet velocity (TRV) was assessed and pulmonary hypertension was prospectively defined as a peak TR jet velocity of at least $2.5 \mathrm{~m}$ / s.

Diastolic function was assessed in all patients using pulsed Doppler peak E and A velocities, E / A ratio and deceleration time. $(\mathrm{E}=$ Peak velocity of early mitral flow, $\mathrm{A}=$ Peak velocity of late mitral flow)

\section{Statistical Analysis}

The statistical analysis was done using software $\mathrm{R}$ version 3.6 .3 (2020 / 02 / 29) and RStudio version 1.3.1056 by chisquare Automatic Interaction Detection (CHAID). The CHAID provides automated significant association for dependent categorical variables for independent categorical as well as continuous variables. 


\section{RESULTS}

Of the 100 patients included in the study, 70 were sickle cell trait cases (AS) and 30 were sickle cell disease cases (SS). There were 18 males and 52 females of sickle cell trait and there were 15 males and 15 females of sickle cell disease. The study was done in various age groups ranging from $15-65$ years, which included 33 males and 67 females. The $15-24$ years age group included maximum subjects with 16 (48.9\%) males and $26(38.80 \%)$ females. The mean age of study population was 29.4 years \pm 11.77 years.

Out of 100 cases, 16 cases (16\%) had haemoglobin ( $\mathrm{Hb})$ level between 4 to $7 \mathrm{gm} \mathrm{\% ,} \mathrm{whereas} 74$ cases (74\%) had $\mathrm{Hb}$ level between 7 to $10 \mathrm{gm} \% .10$ cases (10\%) had Hb levels between 10 to $13 \mathrm{gm}$. \%. Mean Hb level was $8.41 \pm 1.74 \mathrm{gm} \%$.

In the present study, out of 100 sickle cell populations, 50 patients (50\%) had left ventricular diastolic dysfunction. Mean age of patient group with LVDD present was $28.82 \pm$ 11.05 whereas patients' group who did not have LVDD had mean age of $29.98 \pm 12.65$ years.

Left ventricular diastolic dysfunction was almost equally prevalent among females compared to male $(\mathrm{P}=0.51)$. Mean age of women with diastolic dysfunction was $29.37 \pm 9.89$ years, whereas the mean age of men with diastolic dysfunction was $29.82 \pm 10.24$ yrs. Statistically there was no association found between age and LVDD prevalence. $(\mathrm{P}=0.99)$

LVDD was present in 34 (48.57\%) cases out of 70 cases of sickle cell trait whereas out of 30 patients of sickle cell disease LVDD was present in 16 (53.33\%) cases. This study found the prevalence of LVDD in different genotypes is almost similar. ( $\mathrm{P}$ $=0.62$, non-significant)

Out of 16 cases having $\mathrm{Hb}$ level between 4 - 7 gm. \%, LVDD was present in 13 cases ( $81.25 \%$ ), whereas in 74 patients with $\mathrm{Hb}$ level between 7 - $10 \%$, LVDD was present in 33 cases (44.59\%). Among 10 patients of Hb level 10 - 13 gm. \% group, 4 cases ( $40 \%$ ) had LVDD.

This reveals that diastolic dysfunction is more closely associated with lower Hb level. $(\mathrm{P}=0.006)$ The LVDD in SCD patients is associated with anaemia of less than $8.9 \mathrm{gm} . \%$ as seen in the Chi-square Automation Interaction Detection (CHAID) (Figure 1).

The CHAID tree of association also reveals higher prevalence of LVDD in subjects with serum creatinine more than 0.35 units and urea more than 19 units. However, the study excluded renal failure patients, so the impact of renal dysfunction on incidence of LVDD cannot be guessed from the study.

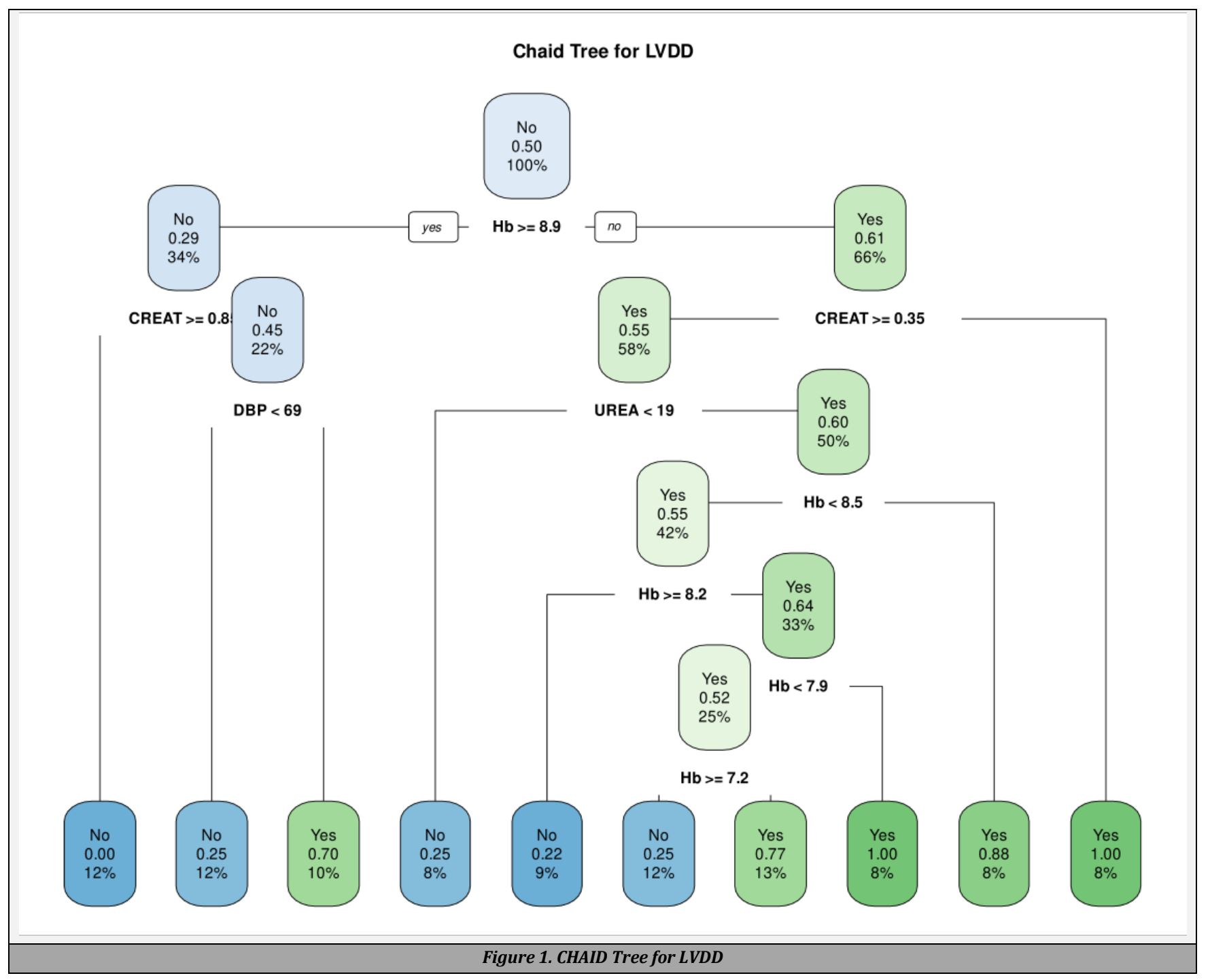





Pulmonary artery hypertension (PAH) was present in 24 (24\%) cases out of the total 100 cases, among them 5 were males and 19 were females. There was no significant difference of prevalence of $\mathrm{PAH}$ between both genders. $(\mathrm{P}=$ $0.14)$.
Though, PAH was most prevalent among the age group of 55 - 65 yrs. which had PAH in $50 \%$ of its population. There was no linear relationship between subjects' age and prevalence of PAH. $(\mathrm{P}=0.91)$

PAH was present in $16(22.85 \%)$ cases out of 70 cases of sickle cell trait whereas out of 30 patients of sickle cell disease 
LVDD was present in $8(26.66 \%)$ cases. There was no significant difference in prevalence of PAH found between both genotypes. $(\mathrm{P}=0.68)$.

All PAH cases had $\mathrm{Hb}$ level $<10$ gm \%. This study suggested that PAH in sickle cell anaemia is more prevalent in patients presented with moderate to severe anaemia then patients having mild anaemia or near normal $\mathrm{Hb}$ level. The $\mathrm{Hb}$ levels less than $8.7 \mathrm{gm} \%$ are significantly associated with increased incidence of PAH. (Figure 2)

The SCD subjects with diastolic blood pressures higher than $69 \mathrm{mmHg}$ had significant association with incidence of PAH. This association became stronger in presence of moderate to severe anaemia. (Figure 2)

In this study, the mean LVEF of the study population was $66.80 \pm 8.24$, while in patients with PAH, the mean LVEF was $66.50 \pm 8.06$ and in patients with LVDD, the LVEF was $66.46 \pm$ 8.93. Only 9 ( $9 \%$ ) cases had $\mathrm{LVEF}<55 \%$, in which 5 patients had LVDD and 3 patients found to have PAH. The LVEF is preserved throughout the SCD subjects in this study. ( $\mathrm{P}=0.68$ for LVDD patients and $\mathrm{P}=0.83$ for $\mathrm{PAH}$ patients)

\section{DISCUSSION}

\section{Genotype Analysis of Study}

Most of the patients included in the study had sickle cell traits than sickle cell disease. In contrast to present study, Pathak who studied 50 patients had 36 (72\%) sickle cell disease and $14(28 \%)$ sickle cell trait. ${ }^{10}$ The high prevalence of sickle cell trait in the study is in contrast to the majority of studies available in the literature, and this difference can undermine the varied outcomes.

\section{Age and Gender Wise Distribution of Cases in the Present Study}

In each age group distribution, female prevalence was observed in the study. The majority of cases in this study were between 15 and 24 years of age. In a study of 235 patients with documented SCD with $60 \%$ cases were females and $35 \pm 11$ years was mean age. ${ }^{11}$ Fakhry studied 45 patients of sickle cell disease, which consist of $82 \%$ male patients and the mean age of his study group was $25.73 \pm 6.79$ years similar to the present study. ${ }^{12}$ Pathak studied 50 patients of sickle cell disease, in which 34 were males (68\%) and 16 were females $(32 \%)^{10}$ Forty six percent of patients in the 14 - 20 year age group were similar to the present study.

\section{Prevalence of LVDD in Sickle Cell Study Group}

In the proposed investigation, there were 100 sickle cell population out of which $50 \%$ i.e. 50 patients were identified with LVDD and their mean age was $28.82+-11.05$ similar to the patient group not having LVDD with a mean age $29.98+$ 12.65 years. However, Sachdev analysed 141 patients having sickle cell disease employing tissue Doppler imaging and evaluated the dominance of diastolic dysfunction in them. ${ }^{11}$ They found that 25 patients (18\%) had evidence of LV diastolic dysfunction. Mohammad Fakhry in his study found evidence of LV diastolic dysfunction in $24 \%$ of 45 patients with SCD. ${ }^{12}$ Zilberman evaluated 73 patients for diastolic dysfunction on echocardiography and found 32 had LV dilatation and 11 had hypertrophy. ${ }^{13}$ Lewis and Maron found that $17(57 \%)$ of their 30 patients with sickle cell anaemia had evidence of abnormal left ventricular diastolic filling. ${ }^{14}$ Hankins measured diastolic dysfunction by TDI (tissue Doppler imaging) in a study group of 30 sickle cell patients and found high prevalence of diastolic dysfunction i.e. 23 (77 \%) of patients. ${ }^{15}$ Eddine Alvarez in their study group of 54 patients of SCD found that $31 \%$ of cases had evidence of LV diastolic dysfunction in tissue Doppler echocardiography. ${ }^{16}$

Due to the limitation resulting from the technique used, there were apparent inconsistencies in the literature concerning the prevalence of LVDD in SCD. These limitations arise due to loading conditions, angle dependency, heart rate or the age of patient. Though TDI techniques employed in the current study were approved by Nagueh MIkati in the general population with invasive measurement of LV filling pressures namely pulmonary capillary wedge pressure, while its accuracy is still to be approved for haemolytic diseases like sickle cell. ${ }^{17}$

Thus, the left ventricular diastolic dysfunction is seen in 18 to $77 \%$ sickle patients among the different studies present. In SCD, increased left ventricular mass and diastolic dysfunction is associated with compensatory hypertrophy of left ventricles, secondary anaemia and left ventricular dilatation along with systemic vasculopathy. The severity of anaemia results in hyperdynamic circulation and is often the result of recurrent haemolytic crises. The repeated crises add to the infiltrative insult to the myocardium causing greater left ventricular diastolic dysfunction.

\section{Association of LVDD with Age}

In the current study, $50 \%$ of cases (21 out of 42 cases) in the 15 - 24 years age group had LVDD followed by $55.17 \%$ (16 out of 29 cases) were in the 25 - 34 years age group. Which is younger in both males and females as compared to Sachdev V et al. ${ }^{11}$ Despite higher incidence in the younger age group, there is no significant disparity between age groups $(\mathrm{P}=0.99)$.

Zilberman in their study of 73 sickle cell patients did not find any correlation between age and diastolic dysfunction. ${ }^{13}$ In a study by Sachdev V et al. out of 235 patients with documented SCD with mean age of $35 \pm 11$ years, (range of age was 18 to 70 years) and 41 age and gender-balanced control patients (mean age $37 \pm 11$ years) they found SCD patients with an E / A ratio of $<1.0$ were older than the remaining patients. ${ }^{11}$ The left ventricular diastolic dysfunction in most of the studies do not correlate with age.

\section{Association between Haemoglobin (Hb) Level and LVDD}

In the present study, cases were divided into three groups on the basis of $\mathrm{Hb}$ level. 16 cases had Hb levels between $4-7 \mathrm{gm}$ $\%$ out of which LV diastolic dysfunction was seen in 13 cases $(81.25 \%) .74$ cases had $\mathrm{Hb}$ level in the range of $7-10 \mathrm{gm} \mathrm{\%}$, out of which 33 cases (44.59\%) had LV diastolic dysfunction. Out of 10 cases whose $\mathrm{Hb}$ level ranged from $10-13 \mathrm{gm} \mathrm{\% ,} 4$ cases (40\%) had diastolic dysfunction. Evidently low $\mathrm{Hb}$ level was associates with diastolic dysfunction. The mean level of $\mathrm{Hb}$ in patients with LVDD in the current study was $7.88+-1.81$ 
gm \% while the patients without LVDD had a mean level of $8.94+-1.49 \mathrm{gm} \%$. There was significant association between the left ventricular diastolic dysfunction and severity of anaemia. $(P=0.006)$. Sachdev V et al. in their study of 226 sickle cell disease patients had LVDD, in which mean Hb level of $9.6 \pm 1.8 \mathrm{gm} \mathrm{\%}$ and control group of 41 patients had mean $\mathrm{Hb}$ level of $13.5 \pm 1.6 \mathrm{gm} \%$ found clear association of LVDD with low Hb levels. ${ }^{11}$ Condurache in their study of 22 patients with SCD also found LVDD is more prevalent in severe anaemia $(\mathrm{P}=.003) .{ }^{18} \mathrm{Johnson}$ founded in his studies that haemoglobin that was not retained with adjustment for multiple comparison has an inverse relationship with LV diastolic. ${ }^{19}$

\section{Association of LVDD with Blood Pressure}

In the present study, systolic mean blood pressure on admission was $101.44 \pm 7.77 \mathrm{mmHg}$ in patients with LVDD and $102.20 \pm 10.41 \mathrm{mmHg}$ in patients without LVDD. The diastolic mean blood pressure on admission was $65.20 \pm 8.63 \mathrm{mmHg}$ in patients with LVDD whereas on patients without LVDD mean diastolic BP (on admission) was $65.36 \pm 9.29 \mathrm{mmHg}$. ( $\mathrm{P}=0.68$ for systolic $\mathrm{BP}$ on admission and $\mathrm{P}=0.92$ for $\mathrm{DBP}$ on admission, both were found to be non-significant). However, the CHAID analysis revealed the left ventricular diastolic dysfunction to be significantly associated with admission diastolic blood pressures above $69 \mathrm{mmHg}$. This association became stronger in presence of coexisting moderate to severe anaemia. The study excluded patients with known hypertension and this association therefore indicates plausible aggravation of diastolic dysfunction by sickle cell haemodynamics.

\section{Prevalence of PAH in Sickle Cell Population}

In the present study, it was founded that out of 100 sickle cell patients 24 were PAH, with 5 (20.83\%) males and 19 (79.16 $\%)$ were females. The patients having PAH have a mean age of $28.92+-13.06$ years whereas patients without it have mean age of $29.55+-11.51$ years. The study also found that $26.66 \%$ patients of sickle cell disease had PAH whereas $22.85 \%$ of patients with sickle trait had $\mathrm{PAH}$, though the difference between two genotypes was statistically insignificant.

Gladwin found $32 \%$ of patients had pulmonary hypertension of sickle cell disease. His study consisted of 195 patients (82 males and 113 females with mean age of $36+-12$ years). Their study did not report any significant difference between sickle cell anaemia and disease group. ${ }^{6}$ Ambrusko had reported a prevalence of $26 \%$ in 44 patients of sickle cell anaemia they studied. ${ }^{20}$ Pashankar reported a prevalence of $30 \%$ of pulmonary artery hypertension in patients with sickle cell anemia. ${ }^{21}$ In a study of 38 patients in Canada by Ahmad [22], $58 \%$ of pulmonary artery hypertension patients were identified with sickle cell anaemia. The estimated mean pulmonary artery systolic pressure (PASP) value was $37.5+-$ 10.9 mmHg. ${ }^{22}$ The estimated mean PASP was $37.5 \pm 10.9$ mmHg. Van Beers in their study found a prevalence of PAH in $41 \%$ patients with sickle cell anemia. ${ }^{23}$ Pathak in his study detected PAH in $34 \%$ (17 out of 50 ) of patients of sickle cell anaemia. ${ }^{10} \mathrm{~A}$ single echocardiography method was utilised as screening tool to diagnose PAH in all of the above-mentioned studies.

\section{Correlation of PAH with Age}

In the present study, PAH was present in 13 (30.95\%) cases of 15 - 24 yrs. age group, whereas 4 (13.79\%) cases of 25 - 34 yrs. age group had PAH. 3 (23\%) out of the 13 cases between age of 35 - 44 yrs. had PAH and out of 10 cases of age group of 45 - 54 yrs. PAH was present in $1(10 \%)$ case. 3 out of 6 cases of age group of 55 - 65 yrs. had PAH (50 \%). It was found to be statistically insignificant. $(\mathrm{P}=0.91)$

Pathak in their study found that advanced age groups among sickle cell patients had higher prevalence for PAH.10 In their study, $75 \%$ of patients in the age group of $31-40$ years and $80 \%$ patients of age group $>40$ years had PAH. ${ }^{8}$ Castro 0 et al. in a study reported that prevalence of PAH increases with age in SCD patients. In 40 - 49 years old prevalence was close to $40 \%$ whereas it increased up to $60 \%$ by age of 50 and above. ${ }^{24}$ Machado et al. in their study stated that advanced age was related to PAH. ${ }^{25}$ In their study, patients with PAH, TRV > $3 \mathrm{~m} / \mathrm{sec}$ had higher age (38 \pm 19 years) compared to those without PAH, TRV $<2.5 \mathrm{~m} / \mathrm{sec}(34 \pm 10$ years). The National Institutes of Health (NIH) PAH echocardiographic screening study showed that patients with PAH were significantly older than patients without PAH. ${ }^{26}$

Though, the present study found higher prevalence i.e. 50 $\%$ among older age groups ( $>55$ years old), the PAH was not associated significantly with any age groups.

\section{Correlation of PAH with Degree of Anaemia}

In the present study, 3 cases out of 16 i.e., $18.75 \%$ of $4-7 \mathrm{gm}$ $\% \mathrm{Hb}$ level had $\mathrm{PAH}$, while in $7-10 \mathrm{gm} \% \mathrm{Hb}$ group 21 cases out of 74 i.e. $28.37 \%$ cases had PAH.

In the study, patients with moderate to severe anaemia were more prevalent to $\mathrm{PAH}$ than those with mild anaemia or near normal $\mathrm{Hb}$ level $(\mathrm{P}=0.59)$. The Mean level of $\mathrm{Hb}$ was 8.54 gm $\%+-1.85$ gm compared to $9.9+1.7$ for patients without $\mathrm{PAH}$. There were no cases of $\mathrm{PAH}$ in the group with haemoglobin above $10 \mathrm{gm} \%$.

Gladwin et al. in their study noted that a lower haemoglobin level was associated with a severe degree of PAH. ${ }^{6}$ The mean $\mathrm{Hb}$ level of patients with PAH was $8.5 \pm 2.0$ as compared to $9.9 \pm 1.7$ in patients without it. Pathak found in their study that mean haemoglobin level was lower in the group with PAH. (Mean $\mathrm{Hb}$ in patients with $\mathrm{PAH}$ was $4.49 \mathrm{gm}$ $\%$ whereas in patient without PAH mean Hb was $6.35 \mathrm{gm} \%)^{10}$

\section{Correlation of PAH with Blood Pressure}

Gladwin in their study had a higher blood pressure in PAH group $123 \pm 23 \mathrm{mmHg}$ as compared to $119 \pm 15 \mathrm{mmHg}$ in patients without PAH. ${ }^{6}$ Pathak did not find much variability in $\mathrm{PAH}$ and non-PAH groups in their study. ${ }^{10}$

In the present study, the prevalence of PAH was not statistically significant with patients having relatively higher systolic blood pressure on admission.

\section{PAH Correlation with Gender and Genotype}

In the present study, 24 patients had $\mathrm{PAH}$, of which $5(20.38$ $\%)$ were males and 19 (79.16\%) were females. In the sickle cell trait population (AS), 16 (22.85\%) had PAH while in sickle cell disease population (SS), 8 (26.66\%) patients had PAH. 
Gladwin in their study did not find any significant differences according to gender and genotype in prevalence of pulmonary artery hypertension. ${ }^{6}$ In the study done by Pathak, there was no correlation according to gender or genotype in prevalence of pulmonary artery hypertension, $(32 \%$ in males and $37 \%$ in females and $33 \%$ in AS type and $35 \%$ in SS type). ${ }^{10}$

\section{Prevalence of Both PAH and LVDD in Sickle Cell Population}

Diastolic dysfunction and pulmonary artery hypertension each contribute independently to prospective mortality in patients with SCD. Patients with both risk factors have an extremely poor prognosis. ${ }^{11}$ In the present study, 12 (12\%) patients had both LVDD and PAH. Sachdev found in 141 patients of SCD, 11 $\%$ patients had both PAH and LV diastolic dysfunction. The presence of both diastolic dysfunction and pulmonary hypertension conferred a risk ratio for death of $12.0(95 \%$ confidence interval 3.8 to $38.1, \mathrm{P}<0.001) .{ }^{11}$

\section{Systolic Function in Sickle Cell Anaemia}

In the present study, the LVEF population was $66.80+-8.24$, while in patients with PAH the mean LVEF was $66.50+-8.06$ and in patients with LVDD the LVEF was $66.46+-8.93$. Only 9 (9 \%) cases had LVEF < $55 \%$, wherein 5 patients had LVDD and 3 patients had PAH.

Sachdev in her study of 235 sickle cell patients found systolic function did not impair significantly $(P=0.2)$. The average LVEF was $65 \pm 8 \%$ (range $42 \%$ to $83 \%$ ), and only 9 $\%$ of patients had evidence of systolic dysfunction with an ejection fraction $<55 \% .11$ Taksande in their prospective controlled study found that left ventricular contraction and systolic function in sickle cell population were as good as comparative study population. ${ }^{27}$ Poludasu in a meta-analysis of 19 studies including 841 SCA patients and 554 control subjects found there were no significant differences in either LVEF (Hedge $g=0.15 ; 95 \%$ confidence interval - 0.84 to 1.14 ; $\mathrm{P}=.76)$ or fractional shortening (FS) $(\mathrm{P}=.28)$ between SCA patients and control subjects. ${ }^{28}$

The present study also concluded that the systolic function is preserved in sickle cell patients. $(\mathrm{P}=0.68$ for LVDD patients and $\mathrm{P}=0.83$ for $\mathrm{PAH}$ patients, both were non-significant.)

\section{CONCLUSIONS}

The present study suggests that sickle cell disease has association with left ventricular diastolic dysfunction and pulmonary artery hypertension and that it may not affect other echocardiographic findings including left ventricular dimensions and functions. The association is further affected by the presence of moderate to severe anaemia, higher urea, creatinine and diastolic blood pressures. The age, gender and systolic blood pressure of the subject were not found to impact echocardiographic parameters. The trend towards effect of renal derangement is seen, but it would be unwise to draw conclusions as kidney disease patients were excluded from the study.

Data sharing statement provided by the authors is available with the full text of this article at jemds.com.

Financial or other competing interests: None.
Disclosure forms provided by the authors are available with the full text of this article at jemds.com.

\section{REFERENCES}

[1] Weatherall D, Hofman K, Rodgers G, et al. A case for developing North-South partnerships for research in sickle cell disease. Blood 2005;105(3):921-3.

[2] Siddiqui AK, Ahmed S. Pulmonary manifestations of sickle cell disease. Postgrad Med J 2003;79(933):384-90.

[3] Belcher JD, Marker PH, Weber JP, et al. Activated monocytes in sickle cell disease: potential role in the activation of vascular endothelium and vaso-occlusion. Blood 2000;96(7):2451-9.

[4] Wood KC, Hsu LL, Gladwin MT. Sickle cell disease vasculopathy: a state of nitric oxide resistance. Free Radic Biol Med 2008;44(8):1506-28.

[5] Gladwin MT, Sachdev V, Jison ML, et al. Pulmonary hypertension as a risk factor for death in patients with sickle cell disease. N Engl J Med 2004;350(24):886-95.

[6] Gladwin MT, Sachdev V. Cardiovascular abnormalities in sickle cell disease. J Am Coll Cardiol 2012;59(13):112333.

[7] Shrivastava S, Kalvit P. Electrocardiographic findings in the pediatric patients of sickle cell disease in Chhattisgarh - a comparative study. IOSR Journal of Dental and Medical Sciences 2020;19(8):15-20.

[8] Shrivastava S, Kalvit P. Blood pressure indices in children with sickle cell disease, of age 8-18 yrs. at a tertiary care centre in chhattisgarh-a cross sectional study. J Evolution Med Dent 2020;9(28):1983-7.

[9] Lang RM, Bierig M, Devereux RB, et al. Recommendations for chamber quantification: a report from the american society of echocardiography's guidelines and standards committee and the chamber quantification writing group, developed in conjunction with the European Association of Echocardiography, a Branch of the European Society of Cardiology. J Am Soc Echocardiogr 2005;18(12):1440-63.

[10] Pathak J, Vadivelan M, Mathew C. Evaluation of cardiac status of patients with sickle cell disease by 2D echocardiography with specific reference to pulmonary hypertension. Indian Journal of Clinical Practice 2013;23(11):694-7.

[11] Sachdev V, Machado RF, Shizukuda Y, et al. Diastolic dysfunction is an independent risk factor for death in patients with sickle cell disease. J Am Coll Cardiol 2007;49(4):472-9.

[12] Abdul-Mohsen MF. Echocardiographic evaluation of left ventricular diastolic and systolic function in Saudi patients with sickle cell disease. J Saudi Heart Assoc 2012;24(4):217-24.

[13] Zilberman MV, Du W, Das S, et al. Evaluation of left ventricular diastolic function in pediatric sickle cell disease patients. Am J Hematol 2007;82(6):433-8.

[14] Lewis JF, Maron BJ, Castro 0, et al. Left ventricular diastolic filling abnormalities identified by doppler echocardiography in asymptomatic patients with sickle cell anaemia. J Am Coll Cardiol 1991;17(7):1473-8. 
[15] Hankins JS, McCarville MB, Hillenbrand CM, et al. Ventricular diastolic dysfunction in sickle cell anemia is common but not associated with myocardial iron deposition. Pediatr Blood Cancer 2010;55(3):495-500.

[16] Eddine AC, Alvarez O, Lipshultz SE, et al. Ventricular structure and function in children with sickle cell disease using conventional and tissue doppler echocardiography. Am J Cardiol 2012;109(9):1358-64.

[17] Nagueh SF, Mikati I, Kopelen HA, et al. Doppler estimation of left ventricular filling pressure in sinus tachycardia. Circulation 1998;98(16):1644-50.

[18] Raj AB, Condurache T, Bertolone S, et al. Quantitative assessment of ventricular function in sickle cell disease: effect of long-term erythrocytapheresis. Pediatr Blood Cancer 2005;45(7):976-81.

[19] Johnson MC, Kirkham FJ, Redline S, et al. Left ventricular hypertrophy and diastolic dysfunction in children with sickle cell disease are related to asleep and waking oxygen desaturation. Blood 2010;116(1):16-21.

[20] Ambrusko SJ, Gunawardena S, Sakara A, et al. Elevation of tricuspid regurgitant jet velocity, a marker for pulmonary hypertension in children with sickle cell disease. Pediatr Blood Cancer 2006;47(7):907-13.

[21] Pashankar FD, Ment LR, Pearson HA. Sickle cell disease complicated by post-streptococcal glomerulonephritis, cerebral hemorrhage and reversible posterior leucoencephalopathy syndrome. Pediatr Blood Cancer 2008;50(4):864-6.

[22] Ahmed S, Siddiqui AK, Sadiq A, et al. Echocardiographic abnormalities in sickle cell disease. Am J Hematol 2004;76(3):195-8.

[23] Van Beers EJ, Van Eck-Smit BLF, Mac Gillavry MR, et al. Large and medium-sized pulmonary artery obstruction does not play a role of primary importance in the etiology of sickle-cell disease-associated pulmonary hypertension. Chest 2008;133(3):646-52.

[24] Castro 0, Hoque M, Brown BD. Pulmonary hypertension in sickle cell disease: cardiac catheterization results and survival. Blood 2003;101(4):1257-61.

[25] Lin EE, Gladwin MT, Machado RF. Pulmonary hypertension in patients with hemoglobinopathies: could a mechanism for dysfunction provide an avenue for novel therapeutics? Haematologica 2005;90(4):441-4.

[26] Haque AK, Gokhale S, Rampy BA, et al. Pulmonary hypertension in sickle cell hemoglobinopathy: a clinicopathologic study of 20 cases. Hum Pathol 2002;33(10):1037-43.

[27] Taksande A, Vilhekar K, Jain M, et al. Left ventricular systolic and diastolic functions in patients with sickle cell anemia. Indian Heart J 2005;57(6):694-7.

[28] Poludasu S, Ramkissoon K, Salciccioli L, et al. Left ventricular systolic function in sickle cell anemia: a metaanalysis. J Card Fail 2013;19(5):333-41. 